Article

\title{
Large Urban Developments as Non-Planning Products: Conflicts and Threats for Spatial Planning
}

\author{
Byron Ioannou ${ }^{1, *}$, Lora Nicolaou ${ }^{1}$, Konstantinos Serraos ${ }^{2}$ and Georgia Spiliopoulou ${ }^{2}$ \\ ${ }^{1}$ Department of Architecture, School of Engineering, Frederick University, 1036 Nicosia, Cyprus; \\ E-Mails: b.ioannou@frederick.ac.cy (B.I.), art.nl@frederick.ac.cy (L.N.) \\ 2 Department of Urban and Regional Planning, School of Architecture, National Technical University of Athens, \\ 10682 Athens, Greece; E-Mails: kserr@central.ntua.gr (K.S.), gspiliopoulou@mail.ntua.gr (G.S.) \\ * Corresponding author
}

Submitted: 11 June 2019 | Accepted: 16 September 2019 | Published: 21 November 2019

\begin{abstract}
The article approaches different concepts of Large Urban Developments (LUDs) as products of the notion of a "spatial fix" (Harvey, 2001), which explains why built or natural environments can be deployed in the process of creating opportunities for new investments. Greece and Cyprus are two countries in the south of the European Union that underwent delayed urbanisation and significant land fragmentation in the form of small size private ownerships and with limited experience in comprehensive development. Greece has adopted a well-structured but complex spatial planning system, bureaucratic with limited effectiveness, adaptability or flexibility of delivery processes. On the other hand, Cyprus has a flexible but centralized system, effective in processing change but problematic in regulating quality in the built environment. Both countries recently experienced major financial crises. In the early 2010s, both governments promoted, as part of an economic recovery policy, extensive real estate development on public or privately-owned land with emphasis on LUDs as ways of addressing economic shortfalls. Inappropriately, LUDs have been primarily "conceived" as opportunities to attract foreign investments rather than a means of tackling crucial current deficiencies. New spatial planning frameworks merely add greater "flexibility" to the system in order to accelerate large private real estate investment. The article attempts to reveal, through case studies' reviews, the impact of LUDs in countries with no infrastructure or experience in accommodating large-scale investment. It explores how the experience in Greece and Cyprus differs in terms of the relevant legislation adopted, the effectiveness in fulfilling its primary objective in attracting investment, and what are the possible social and environmental consequences on the planning acquis.
\end{abstract}

\section{Keywords}

large urban developments; planning framework; spatial fix; spatial planning

\section{Issue}

This article is part of the issue "Large Urban Developments and the Future of Cities" edited by Efrat Eizenberg (TechnionIsrael Institute of Technology, Israel).

(C) 2019 by the authors; licensee Cogitatio (Lisbon, Portugal). This article is licensed under a Creative Commons Attribution 4.0 International License (CC BY).

\section{Introduction}

The main objective of the article is to investigate processes and delivery models of Large Urban Developments (LUDs) in Greece and Cyprus. LUDs, in terms of their economic reasoning, are approached through the notion of "spatial fix" (Harvey, 2001). Both
European Union (EU) countries experienced a serious economic recession during the early 2010s and used means of prioritization in attracting global real estate investment as one of their main recovery policies. A distinct difference, which makes for an interesting comparison, lies in the impact of institutional and planning frameworks in the development process and outcomes. 
The Greek planning appears to be significantly influenced by local interests/pressures which often shape the outcome of LUDs, whereas in Cyprus top-down decision making is strong and decisive in swiftly delivering projects. Key questions are: How far do the temporal trajectories of each case lead to different forms of spatial development? What are the terms of reference in each case? And what may be the future of long-term planning practice?

The article begins its investigation from a critical assessment of the top-down planning systems of both countries focusing on the planning tools that promote the effective implementation of the LUD policy. Comparative conclusions are drawn from the evaluation of three aspects of current practice: the nature of planning frameworks; how effective they are in delivering LUDs; and what the impact would be on the associated physical and environmental contexts. Key differences between Greece and Cyprus in LUD practice, like the preferred locations and development types, are highlighted.

Case study evaluation is one of the key methodological tools which focuses on parameters such as the relevance of projects to their wider conventional spatial and planning contexts, the discrepancies in the way special issues arising are managed, the consideration of environmental implications, the effective policy delivery in relation to initial objectives and, finally, the views of local communities in considering their associated values and impacts.

The article attempts to verify whether the comprehensive added value of LUDs for these regions is a positive aspect or if it simply constitutes a "spatial fix" of global economic activity.

\section{Global Challenges, New Requirements for Spatial Planning and the "Spatial Fix"}

During the past decades, a surplus of global investment funds alongside the supposed "security" of real estate investment became the basic premise for a trend, which can be observed worldwide, combining "ease" and "attractiveness" in property investment practices (Sisson, Rogers, \& Gibson, 2019). Foreign Direct Investments (FDI) have become a crucial agent of economic development and competitiveness among cities and regions. Between 1990 and 2011, FDI increased almost 200\% globally (Kalafsky, 2012). During the same period, an increasing proportion of wealth-almost $8 \%$ of the global GDP-was kept in offshore domains, seeking opportunities to launder itself through a network of companies and service providers that use real estate and property investment as a preferred vehicle (Cooley, Heathershaw, \& Sharman, 2018). In this context, LUDs created a sophisticated economic strategy involving global real estate agents, research centres, engineering and software development firms, material and construction system providers, etc. (Nethercote, 2018). Furthermore, global forums such as the Council of Tall Buildings and Urban
Habitat (CTBUH) promote the idea of LUDs. CTBUH is active worldwide as a resource for professionals supported by influential global stakeholders: 26 of them come from Italy, Spain, France and Greece; 15 from Israel, Turkey, Lebanon and Egypt. This probably indicates an emerging global interest for this type of development in the Mediterranean Region.

Financial downturns contribute to the transformation of this latent dynamic into political pressure for the introduction of emergency planning frameworks. In most EU countries, a combination of re-forming and bypassing restrictions of formal planning was the answer to this new challenge (Reimer, Getimis, \& Blotevogel, 2014). In this context, Greece-and to a lesser extent Cyprus, where the national economy was operating for several years under bailout programs-fast-tracked the design and adoption of special planning tools associated with real estate investments on public and private land in order to increase attractiveness for investors (Serraos, Greve, Asprogerakas, Balabanidis, \& Chani, 2015). Factors such as the attractive and, in many cases, unique coastline, the Mediterranean climate, natural beauty, tax incentives and a tourism industry with a potential for growth created quick and easy investment channels.

Harvey describes how the global boom-bust cycles in the built environment related industries facilitate temporary "fixes" of the capitalist system, smoothing crises caused by over-investment or over accumulation (Clarno, 2019). The idea of "spatial fix" (Harvey, 2001) explains why built or natural environments can be deployed in the process of creating opportunities for fresh investments in order to absorb the pressure of the global over-accumulation (Jessop, 2010). Furthermore, Mayer (2017) highlights that major actors that develop cities and regions as mediators of global capital often form powerful alliances that assist in prioritising their interests rather than those of the local population (Büdenbender \& Golubchikov, 2017).

In this context, the impact of "territorial entity" and its different temporal trajectories are extremely effective on the forms through which over-investment is realised in different spatial contexts (Harvey, 2001). Governance could be seen as a spatio-temporal trajectory that defines the footprint of global investments on land space. Planning and property development are complex aspects of governance, different in each case, with different resistances in top-down management (Jessop, 2010). Since the competition among states and regions for the attraction of global real estate investments is growing, central states are seeking ways to strengthen their executive authority on planning in order to become more effective in absorbing international funds (Jessop, 2010). This approach sometimes leads to the abandonment of long-term planning (Harris, 2019). The public authorities, therefore, find themselves as managers of these "firms following the logic of business management, being engaged in product development and marketing" (Madanipour, 2006). 


\section{The Formal Spatial Planning System in Greece and Cyprus}

European planning systems and their instruments and policies differ considerably (EU, 1997), which makes comparison valid only on the basis of their output.

The Constitution of Greece is the cornerstone of planning policy. Along with the safeguarding of the right to property, it states that "the right to property therein may not be detrimental to the general interest" (Hellenic Republic, 1975). For public utilities, ownership may therefore be expropriated in all cases with full compensation of the land. "The protection of the natural and cultural environment," as well as the "territorial restructuring of the country, development, urbanization and the extension of cities and residential areas in general" (Hellenic Republic, 1975) fall within the obligations of the State. Within this general framework, laws $947 / 1979$ and $1337 / 1983$ attempted for the first time to introduce a comprehensive spatial planning system in line with international practice. In the 1990s, two new laws, 2508/1997 and 2742/1999, were introduced in order to regulate all planning procedures with the deployment of a wide range of tools covering planning at a national scale and concluding with the establishment of urban plans (Angelidis, 2000; Serraos, 2007).

Despite the fact that the country had a comprehensive spatial planning system, effective spatial governance in practice was only partially possible since substantial weaknesses that emerged connected time-consuming procedures; delays in establishing the National Land Registry; the unsecured and erratic flow of associated financing; and finally the inability to reconcile opposing interests in the use and management of the space (Koudouni, 2014). Indicative of these problems is the fact that, after more than 30 years, a binding clear designation of land uses has not yet been finalized, while in parallel the building control system continues to show considerable deficiencies (Koudouni, 2014).

More recently, laws 4269/2014 and 4447/2016 (Hellenic Republic, 2014, 2016) were launched with the principal objective to "improve the coherence and functionality of the spatial planning system." This new legislation is clearly interested in the accommodation of a desperately needed "flexibilization" of the planning system in relation to the facilitation of investments, which at the same time is supposed to exacerbate spatial fragmentation (Serraos, 2014). The current spatial planning system in Greece facilitates this objective by distinguishing the Strategic Planning (Special Spatial Programs and Regional Spatial Programs) from the regulatory level of Development Control. The latter also operates on two levels; the first refers to Local Spatial Plans (LSPs) and Special Spatial Plans (SSPs), and the second to Urban Planning Implementation Plans. It is argued that the SSPs serve the extraordinary and special needs of space development and weakens the regulatory planning value of the LSPS (Melissas, 2010). By operating at the same planning level, they work in parallel and compete with the formal "regulatory" urban planning at the local level. SSPs in particular can also easily and quickly modify the regulations of the LSPs, as well as of any other specific urban planning local regulations, especially when they concern permitted land uses and building regulations and restrictions.

Regarding the equivalent regulatory conditions in Cyprus, the post-colonial 1960 Constitution pays almost equal attention to the human right of private property and to the right of the State to intervene in private property for the common interest, especially in relation to planning and development (Republic of Cyprus, 1960). Due to the Turkish invasion and the spatial division of the island, the Planning Law was not enforced until 1990 and neither was the "Island Plan" nor has any kind of national spatial planning framework materialised so far (loannou, 2016). The Constitution and the Town and Country Planning Law of 1990 gives the Government and the Minister of Interior the aggregated power to decide on all planning issues. The 1990 Law also recognises the deficiencies and defines the need for three levels of spatial plans: a) "Island Plan" to cover the whole territory; b) "Local Plans" for the main conurbations and other specific regions and a "Policy Declaration" which includes the general text and zoning maps for the rural areas; and c) "Area Schemes" which are detailed district and urban plans that have had a very limited application so far. The system continues to be incomplete with only the middle scale of intervention being fully developed (Ioannou, 2016, 2019).

The Minister of Interior was granted the authority of preparing "Local Plans" and "Area Schemes" to an independent "Planning Council" but acts its authority on the final draft of all plans. The Minister also intervenes through horizontal "Orders" and "Circulars" which can be published at any time if specific issues arise, more often through various political pressures than environmental ones. Furthermore, the Council of Ministers exercises from time to time its supreme authority on specific and general issues by passing the provisions of the official plans. These conditions of extended discretionary powers for a case by case planning decisions without a clear framework of procedures for deciding particularly large development plans, often and in principle, weakens planning practice. In some cases, planning authorities when pressured might be vulnerable to prioritising the benefit of individual owner groups, developers and investors (loannou, 2016). It is also important to understand that the development-planning context in Cyprus lacks a planning culture. Furthermore, the effort of building a planning culture after 1990 was slow but positive until the 2013 financial crisis (loannou, 2016), after which all development activity stopped, and several developmental factors were again put on hold.

\section{LUDs' Nature and Special Planning Context}

Where piecemeal change clearly shapes "places" in the long run, LUDs are step changes not only of local environ- 
mental significance but with impact on the norms and behavior of future development practice.

In Greek legislation, the concept of LUDs first emerged during the financial crisis in 2010, when important investments were considered "strategic" because of their potential for positive contribution to the country's economy. The main spatial tool for servicing LUDs is the SSPs (Hellenic Republic, 2016a). The specific forms of the SSPs are: the ESCHADA plans (Special Spatial Development Plans for the Public Property; Hellenic Republic, 2016b), which refer to private real estate investments in privatised State property, and the ESCHASE plan (Special Spatial Development Plan for Strategic Investments; Hellenic Republic, 2010). The latter refers to investments in private land considered "Strategic Investment" (in accordance with the corresponding law, which provides associated benefits and incentives). From 2014 onwards, the frameworks of SSPs can be used for any major private or public projects deemed to require particular spatial regulation of planning parameters and aspects regarding land use and building capacity. Such special circumstances vary from projects relating to the regenerating of urban areas, the rebuilding and transferring of landslide urban settlements or even the constructing of large department store buildings (Hellenic Republic, 2014). Proposals are obliged to comply with the country's strategic plans, i.e., the Regional Spatial Planning and the Special Spatial Planning Frameworks. In addition, SSPs also comply with legislation for the protection of the environment, forests, cultural heritage, defence and national security. The adjustment to these frameworks secures, to an extent, a level of alignment with planning principles.

SSPs, which are designed for large investments, apply to both urban and rural lands. Nevertheless, in most cases, LUDs are planned in areas outside local plans where land is cheaper and therefore such projects become more profitable (Spiliopoulou, 2018). An exception to this trend concerns the upgrading of existing urban developments, mostly shopping malls (i.e., Maroussi/Athens), where the local plan does not normally allow for further expansion. To date, the SSPsas defined by their specific legislation-have been used to give the property a planning and investment character including land use and building capacity designations and the specific requirements of the urban planning legislative frameworks (such as environmental impact assessments, demarcation of boundaries of natural landscape elements, protection of antiquities, forests, seashores, etc.). However, it is noted that, while SSPs are designed to stimulate investments mainly towards the innovation and technology sectors, in practice they are initiated mostly for LUD construction projects, particularly in the tourism sector.

By utilizing these special spatial tools, rural or natural areas with very low development prospects are becoming development zones through fast track procedures. Whereas planning procedures seem successful in shift- ing land designations, the delivery of projects and the associated specific spatial tools show certain malfunctions. According to the officially approved projects (Hellenic Republic, 2010, 2012, 2013, 2014, 2015, 2016a, 2016b), 18 "Strategic Investment" projects were confirmed until the end of 2018, while only two have been further elaborated through the ESCHASE process. For publicly owned land managed through the Hellenic Republic Asset Development Fund (HRADF), only seven ESCHADA plans were authorised. There are still no approvals of proposals outside the SSPs noted above, where until 2019 no major development approved through the SSPs' tool had been implemented and none had completed the licensing procedures in order to begin construction. This evaluation suggests that LUDs would not have been feasible within the conventional planning system and at the same time, special spatial tools seem not to be sufficient as a mechanism for their effective delivery. Simultaneously, and because of this special treatment of LUDs, they have been particularly criticized by the academic community (Serraos, 2014) as being favourable for investors but having adverse consequences for the environment and its protection. The concern is that although the state facilitates investments by granting favorable conditions and tools leading to large capital gains, this whole endeavour does not seem to have been effective enough so far in delivering change or major local economic benefits.

Other factors and considerations at a national level which limit the attraction of foreign investment are the lack of confidence in the local economy and administration; the level of predictability of forecasts; the lack of consistency and certainty; the speed and ease with which cases are handled; etc. (Greek Industrialists' Association, 2018). Furthermore, and from the experience of processing the first five LUDs, it seems the state ought to ensure both sufficient funding for supporting the implementation of projects by investors and compensatory benefit for local societies in order to be able to unlock the delivery of such large projects. As shown by the review of case studies in this article, one of the major stumbling blocks in the detail planning of large proposals is the necessary approvals and signings-off through public consultation needed for projects to become reality. Above all, however, it is necessary to realise that in cases where there is no interest by investors, the implementation of a LUDs driven primarily by the public sector will take much longer.

Whereas LUDs in Greece seem to remain "on paper," the shape of Cyprus' cities has been dramatically transformed by large-scale projects during the last years.

The range of projects, which can be characterised as large-scale developments in Cyprus, differs considerably from the practice in Greece. Large-scale out of town developments based on international models and comprehensive tourist resorts/villages, similar to the ones proposed in Greece, have been part of the urban landscape in Cyprus particularly since 1974 . Such development aim- 
ing lately at specialised, higher value markets, continues to prefer rural locations of high environmental values, acquiring planning approvals through procedures very similar to the ones described in the Greek examples. The introduction of emergency mechanism for the delivery of investments and the emphasis on LUDs affected similarly the Cyprus planning system (Council of Ministers, 2016), especially since 2013 with incentives often associated with increased capacity compared to the official plans' designations.

The availability in high value lands within built-up areas leads to large-scale proposals in urban areas often very close to the traditional city centres and coastal strips. Because of the difficulty of land assembly in urban areas, increased capacity can only be achieved through taller structures that indeed constitute the majority of LUD proposals during the last 10 years (mainly residential developments). Figure 1 shows the dramatic change in the landscape of the city of Limassol with the towers representing sites where planning approvals were or are allowed to be granted. While the capital of Cyprus, Nicosia, does not indicate the same level of pressure, the consideration of such development is similarly taking place in the total absence of locally specific planning frameworks simply on the grounds of lack of any other type of large-scale investment proposed by the private sector (Ioannou \& Nicolaou, 2018). There are clear inadequacies in the following: building control; environmental assessment of regulatory frameworks; technical know-how associated with their construction and/or research on aspects of long-term viability and the effect of their social and cultural impact, etc. (Ioannou \& Nicolaou, 2018). In stark contrast to the situation in Greece, many approved projects are constructed at a very fast pace, in a context of total lack of consultation (public or institutional), changing overnight the urban landscape of Cyprus' cities.

In contrast to Greek practice, changes to the planning and development control framework are prepared more at the political planning level, rather than at the administrative one. This lack of specificity and legitimisation of processes relates to all LUDs, including tall buildings. The term LUDs does not have a specific mention in the formal Cyprus planning or legislative frameworks. Furthermore, the term "Urban" is not appropriately defined, with a lack of clarity in areas which are considered urban in contrast to suburban or rural lands with only the boundary of "development zones" marking areas where Development Plans apply. The only clear statutory designation refers to the Central Urban Areas that are clearly and accurately demarcated on maps for each of the Local Plans enveloping mainly the traditional historic city centres.

The legislation is also unclear on the term "Large Developments." The study of official planning documents clearly indicates that a development in a plot larger than four conventional residential building plots $\left(2,000 \mathrm{~m}^{2}\right)$ and/or in some cases of a scale larger than $5,000 \mathrm{~m}^{2}$ is considered a LUD. Such definitions are independent of location, environmental significance or other compositional characteristics (density, mix of uses, etc.). At the "Local Plans" level the situation is similar, with no reference to structured strategies for the LUDs during the past thirty years. The issue of small-scale land fragmentation, dispersed multi-ownerships and the ineffectiveness of the real estate industry to provide sufficiently large development parcels at the centre or even the periphery of the city centres is referred to repeatedly in the text of Local Plans as a major hindrance toward regeneration and renewal (loannou, 2016). Attempts by incentive measures in Local Plans are mainly quantitative, where offering percentage increases in the cases of land assembly is proven not to be effective so far (Ioannou, 2016). An exception to this lack of references is the policy for "Integrated Developments of Large and Complex Land Uses" noted in all official plans, which aims specifically at the facilitation of strategic large-scale investments on research, health, higher education, culture and

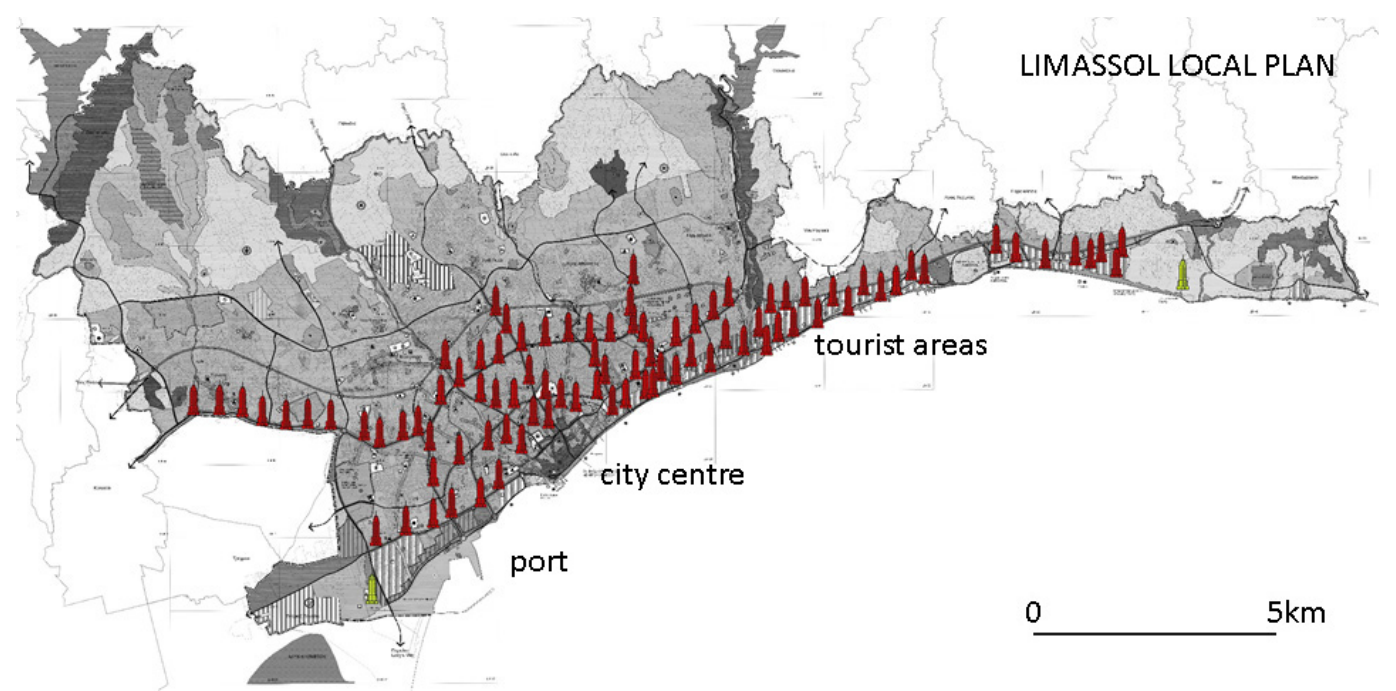

Figure 1. Exercise of possible high-rise LUD locations using Limassol Local Plan as background. Source: loannou and Nicolaou (2018). 
sports. Such investment is proposed almost everywhere at the periphery of the cities and the countryside, leading often to pepper-potting of key amenities across the Island's countryside with insufficient infrastructure provisions, high accessibility, etc.

Just after the 2013 economic crisis in Cyprus, similarly to Greece, there has been a stronger push by the Government to encourage Large Developments as a means of attracting foreign investments. The Council of Ministers enacted its horizontal powers-allowed by relevant legislation-and bypassed the official planning system with a new incentive plan (Council of Ministers, 2016). This plan benefitted plots larger than $1,000 \mathrm{~m}^{2}$ by an additional 0.30 building coefficient if the development was in the designated central urban districts. The plan also benefitted other types of urban or countryside developments but focused particularly on tourist areas and commercial streets. The planning context also allowed the accumulation of additional building coefficient from various incentives (listed buildings conservation, renewable energy, etc.). This plan was criticised by several distinguished journalists and academics as deriving from or being relevant to the Government's "Scheme for Naturalization of Investors in Cyprus by Exception," which essentially provided a European passport in exchange for a $€ 2.3 \mathrm{M}$ personal investment on the island (Republic of Cyprus, 2014; loannou \& Nicolaou, 2018). In this context, one can hardly suggest that the Cyprus planning context promotes LUDs in a controlled and structured manner.

An exception to the loose and discretionary framework of the Local Plans is the new generation "Local Area Plans," which are beginning to be prepared for the central areas of four big cities. The Nicosia City Centre Area Scheme (NCCAS), enacted in 2016, covers less than 5\% of the urban conurbation of the city and it designates a specific central business district where increased building density and permitted height are maximised in a compact area of approximately $1 \mathrm{~km}^{2}$.

In 2018, after pressures from society and various stakeholders both objecting to tall buildings, the Director of Planning published a circular on High Rise developments setting several criteria for permitting high rise development-most non-specific and non-binding, failing in this way to clarify the development framework for LUDs (Department of Town Planning and Housing, 2018a). In actual terms, the new Directive legitimises more than it regulates the liberalisation of height and densities in urban areas.

This context clearly reveals that the Cyprus planning context fails to promote LUDs in a controlled and structured manner or in one which can maximise the benefits of large-scale inward investment locally. Most fragments of policies are designed to facilitate the delivery of private developments assisted by policies of economic growth set by the central government agenda with no due consideration of spatial or environmental benefits or impact.

\section{Case Study Review: Selected Recent LUDs in Greece and Cyprus}

The case studies reviewed are drawn from the period post-2010 during which the most recent and unexpected economic crisis emerged in the wider South Mediterranean region (Hadjimichalis, 2014). The concept of LUDs as well as the need to develop and institutionalise appropriate planning tools is inextricably linked to the intense efforts to overcome quickly this economic crisis.

Two real case studies in Greece chosen for review concern large tourist investments and represent the first examples of approved integrated town planning proposals; the first on public land (ESCHADA) and the second one on private sector property (ESCHASE). Neither case, however, initiated construction until the beginning of 2019.

The development of Kassiopi on Corfu Island is the first example illustrated in Figure 2. It is located along the coast within public land of exceptional beauty and high environmental quality. It covers 447 acres (265 acres of forestry land). In 2012, after the transfer of the property ownership from the State to the HRADF in the form of shares, the tender and a public competition for its exploitation was issued. With a Presidential Decree in 2013 (Hellenic Republic, 2013), its spatial destination was approved in order to allow building on a natural landscape lacking spatial planning policy, the terms of its construction and the Strategic Environmental Impact Study. In 2016, the Area Planning Study was approved (Hellenic Republic, 2016a), the building conditions and the land uses per building block were specified and the necessary restrictions were set for the protection of cultural and natural features. The environmental conditions for the construction of all the necessary infrastructure projects were also approved. Upon the completion of the procedures noted above, HRADF transferred to the investment group a portion of the land in a form of a lease for 99 years, in order to be used in accordance with the urban plan already approved by the State. In 2017, the full ownership of the plots intended for the construction of residences was also awarded. $50 \%$ of the utilised land is being transferred to the Municipality (roads and communal areas), while the forest areas and the beach zone remain as public spaces with free access.

The local authorities reacted negatively toward the project from the beginning and appealed to the Council of State but without success. Additionally, nine court appeals-between 2012 and 2018-called for the cancellation of the project, all of which resulted in rejections. Despite all the positive legal outcomes concerning the project, until the end of 2018 the project had failed to secure all the necessary construction permits (building permits, authorizations for interventions, etc.). This is despite the fact that both the central government responsible for the procedures up to the approval of the urban plan and permits as well as the supportive approach of 


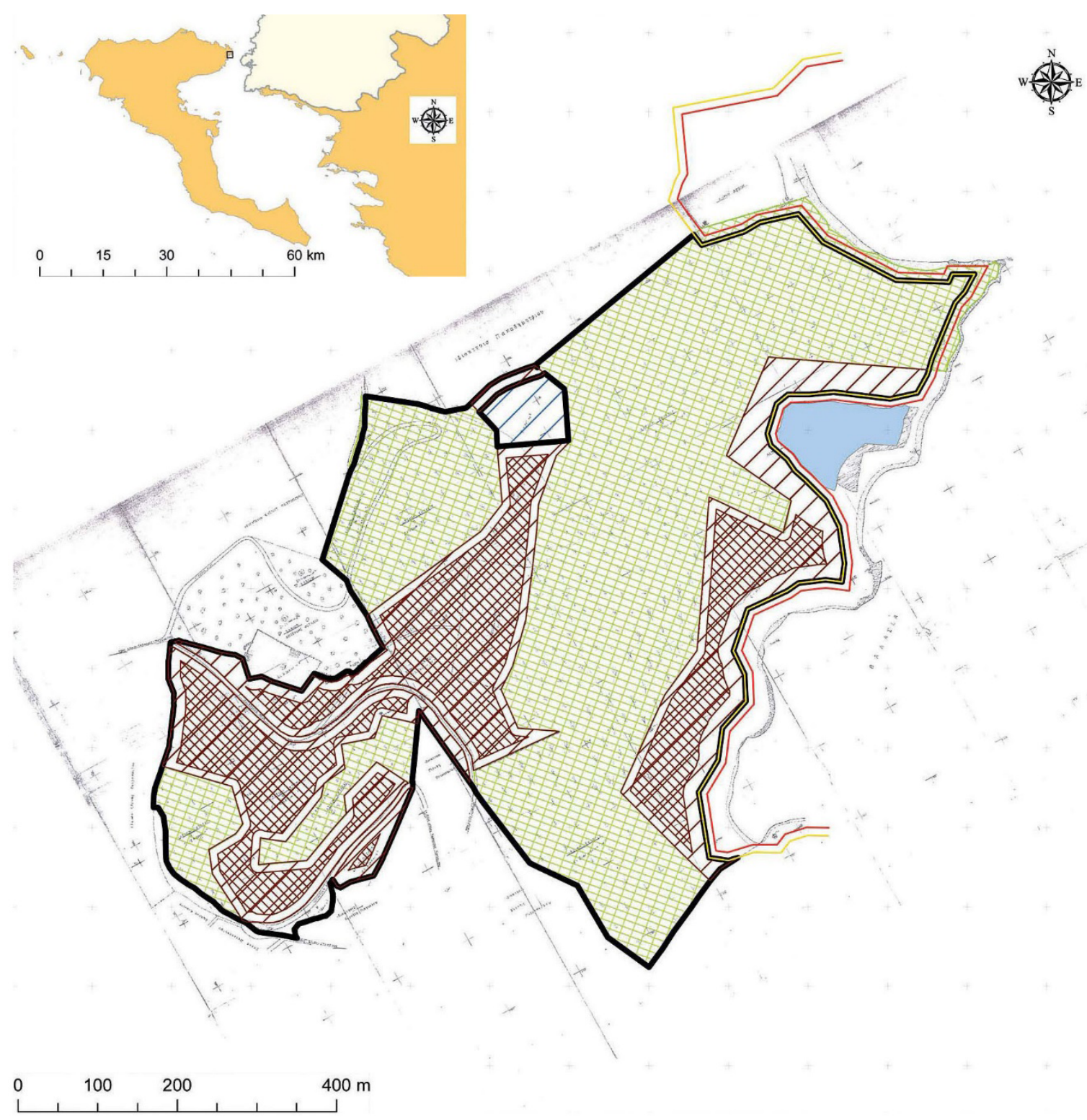

Figure 2. Special Spatial Development Plan for Kassiopi, Corfu, showing the boundaries of the estate, the development zones and the protected areas. Source: Hellenic Republic (2013).

the courts have managed very quickly to comply with their responsibilities and grant the necessary planning approvals. However, the implementation of the project cannot yet begin due to the ongoing opposition of the local community, which prevents the local authorities from granting the necessary building, and other permits still under their jurisdiction, with equal ease to the investment group.

The second example concerns the development of the holiday resort "Killada Hills" in Argolida, near Porto Heli, covering an area of approximately 2,100 acres near the sea. It is an area close to the capital Athens with remarkable spatial features combining a beautiful shoreline, tranquil scenery, very important ancient monuments and high-level cultural destinations/activities in the vicinity (Figure 3 ). The project is an investment on a private land that took several years for its plot-by- plot acquisition and encountered great difficulties when the investors' attempts to get the necessary approvals through the conventional procedures proved unsuccessful. Unlike the case of Kassiopi, there seems to have been no significant reaction by the local community to the realisation of the project since there were no court appeals or negative references published. For this reason-and since 2013-the process of approval of the scheme proceeded at a relatively fast pace, while with the adoption of the relevant ESCHASE in 2015 (Hellenic Republic, 2015) all planning issues were resolved. At the end of 2018, the Joint Ministerial Decision approval of the Town Planning Study and the Environmental Terms for Projects and Infrastructure was published (Hellenic Republic, 2018) and, according to reports, earthworks have recently begun. It also appears that, according to press reports, the project's financial difficulties have also been overcome. 


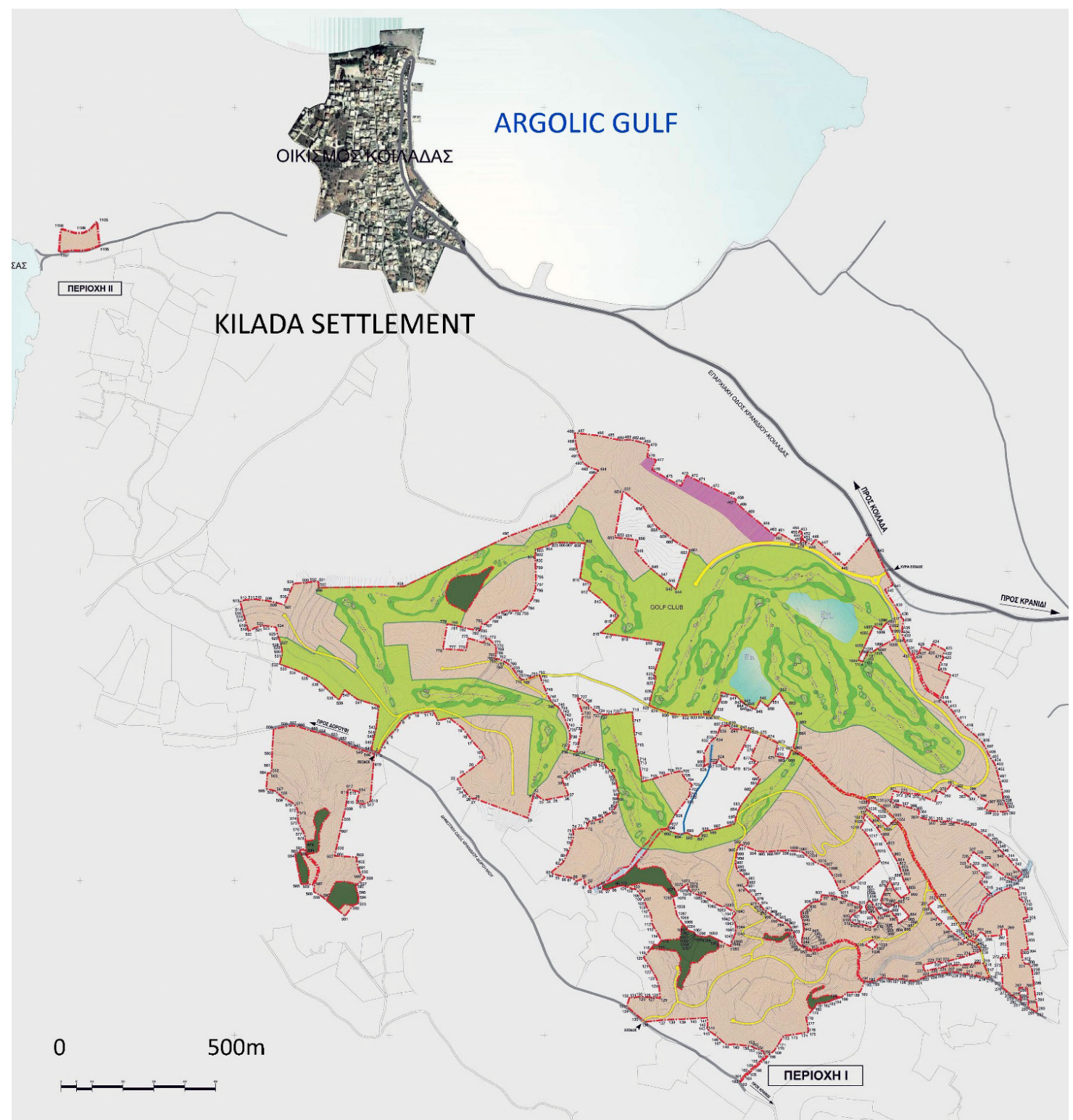

Figure 3. Killada Hills. Special Spatial Development Plan indicating the development zones (pink) and the golf course area (light green). Source: Hellenic Republic (2015).

In the case of the "Killada Hills," the acceptance by the local community has contributed significantly to the promotion of the project and eventually to the relatively quick start of the works. The approval of the Urban Planning took three years from the approval of the first stage (the Presidential Decree), which in turn took just over two years from the "official" launch of the project as part of the state's relevant procedure. The respective time for the approval of both planning stages for LUDs was five years (land designation processes and planning approvals), in contrast to the official system of planning which is estimated to take 15 years at least (Spiliopoulou, 2018). This is mentioned in order to explain the level of acceleration of planning process towards approval with special spatial planning tools.

Although in the case of Kassiopi the development takes place mainly in a forestry area it is a mild in- tervention into the environment, in contrast to the dynamic intervention of Killada and specifically the size of the project in relation to the existing village. Despite that, the project will be realised in a rural, nonprotected environment.

Whereas in Greece the full implications and impact of the delivery of the LUDs' case studies referred to here cannot be assessed, in Cyprus the construction of tall developments is beginning to emerge at a very fast pace. Unofficial data from the Department of Town Planning and Housing in January 2019 indicate that already 200 applications for LUDs had been submitted, primarily in Limassol, by Spring 2019. Approximately 12 of those are completed and occupied, some additional 28 of them are currently under construction, while 15 have been approved by the planning authorities. The time needed by the planning authority to examine and approve the ap- 
plication is officially the same as any other application of similar complexity. The scale and often derivative height of proposals varies primarily according to the scale of the market and the nature of the developer/builder (Department of Town Planning and Housing, 2018b). This article examines two cases in Nicosia, one which represents the planning framework valid prior to 2013, and a second more recent one that encompasses the evolution of the planning framework. The second set of case studies describes the typical conditions in Limassol, which emerged as a direct result of the 2013 economic depression and attempts for the revitalisation of the economy.

Nicosia's interest in taller structures began in 2003 with the proposals for an architectural landmark central location along the moat of the 16th century Venetian walls of the city. Tower 25 was commissioned to the reputable French architect Jean Nouvel. A planning permit using the discretionary power of the Director of the Planning Department was given in early 2010s, prior the 2013 incentives and the 2016 NCCAS provisions that created a more beneficial environment for taller developments. At 62 meters high, it was the 4th tallest building in Cyprus at the time, where now it is clearly dwarfed by more recent proposals, and was delivered at the beginning of 2013 when the economic crisis became apparent. It was originally conceived as a residential building, a decision which was revised at later stages of its feasibility allocating the lower seven floors to high value office space with apartments above. The $€ 25 \mathrm{M}$ construction cost was considered extravagantly high and its real estate value was never established since none of the accommodation became available for sale or rent in the open market. Most of the accommodation was kept as an investment by the development company-Nice Day Developers - and was sold through internal private deals. The development is around $7,000 \mathrm{~m}^{2}$ in a plot of $1,200 \mathrm{~m}^{2}$. Its related planning gain amounts to merely a narrow public plaza (Ioannou \& Nicolaou, 2018) at the front entrance of the building. This case might indicate the unaffordability of luxury accommodation or the low "commercial profitability" of LUDs prior the 2013 transition.

A second similar example of the Leventis Gallery was proposed a few years later and completed in the mid of the economic recession of 2013, and it portrays the same characteristics: privately owned luxury residential accommodation, owner occupied, near the city walls, and not part of the real estate market. A striking difference of this development, which makes it unique in Cyprus so far, is the contribution of the building to the social and cultural life of the city with the three lower floors of the building open to the public accommodating the first contemporary art gallery in Nicosia.

The first speculative residential building proposed in Nicosia- "360 Nicosia"-is by far the tallest, with 27 floors of residential accommodation and 7 floors of support amenities and ground floor retail (Cyfield Group, 2019). The site is a considerably larger plot of $2,000 \mathrm{~m}^{2}$, with around $25,000 \mathrm{~m}^{2}$ of built space. The building lo- cation falls within the tall buildings' framework of the NCCAS (Ioannou \& Nicolaou, 2018), which allows unlimited height and capacity to the site. The development has accumulated all the plot ratio and height incentives that are allowed by the state and purchased extra building coefficient from the local municipality. One other difference from the previous examples is the fact that this building was not designed by a "signature architect." This probably indicates the confidence of the local development industry in delivering a relatively conventional high profitability building. The turn of events in the relatively conservative Nicosia market clearly shows the shift of the initial interest from the LUDs as branding tools to profitmaking large-scale projects.

Developments in the coastal city of Limassol are all speculative, driven by super profits on lands designated for conventional 5-6 storey buildings and are already built and occupied with 16 under construction, all of different scales, height, shapes/morphological character and all used the discretional planning powers of the Planning Department for their approval. Approvals were negotiated with very little planning gain (often small parcels of publicly accessible space) which is very rarely delivered. In most cases, the full site is privatised as tenants' amenity turn blank walls onto the periphery of the site, with negative impact on surrounding neighbourhoods. The urban formation of towers is inevitably dispersed among its $20 \mathrm{~km}$ coastline (Figure 1 ) in order for each building to benefit from the sea view, a condition determined by demand despite the fact that the Local Plan has stated in relevant studies a set of preferred locations. The extent of this dispersal is only now beginning to raise objections from the public and local media, as they are seen as unwelcome implications caused by discrepancies of scale (Ioannidou, 2018).

One other distinct difference in LUD in the coastal cities is the market the building refers to and the type of clientele. In Nicosia, residential units refer mainly to the local markets or newcomers employed by enlarged international firms. Most of the Limassol buildings draw buyers from the "Scheme for Naturalization of Investors" (Republic of Cyprus, 2014), a fact that very much reflected the vast difference in sale values across the two. In these terms, the alteration of the city's character is not only physical but social and functional, conditions which are noted by the local community and begin to create reactions and objections in the way the public sector regulates this type of LUDs (Ioannou \& Nicolaou, 2018).

\section{Conclusion}

Formal planning frameworks in both cases have showed a weak trajectory in defining the footprint of global investments on space, while community reaction and bureaucracy seems to be more decisive in slowing and moderating change.

In both cases of Greece and Cyprus, LUDs are regarded as opportunities to benefit from the "spatial fix" 
of international capital, rather than a means of improving either planning practice, local economies or the environment. Such policy in Greece so far has activated large parcels of "cheap" public and/or private land through fast track procedures, which provide legally binding spatial planning conditions designed to stimulate large-scale investment. Development policy in Cyprus facilitated LUDs by providing incentives well over and above the already flexible spatial planning through discretionary political powers resulting often in unregulated, fast track urban interventions. In both cases, the fragments of supplementary policies influence the "planning acquis" through the establishment of mechanisms that easily bypass the formal spatial planning system and its interest in structured planning, detailed considerations of impact and environmental quality. One other consequence, which becomes increasingly obvious, is the emergence of a common approach of a public policy shift of the decisionmaking process from the local planning authorities to the central state and away from local concerns. The flexibilities this change implies lead towards favouring LUDs more than any local considerations or benefits.

Although this strategic shift of dynamics and the economic and urban development challenges are similar in both countries, the corresponding institutional frameworks, processes, tools, planning context and development outputs differ significantly. While Greece features a well-structured formal planning system referring to all scales of planning as well as the special tools for LUD's purposes, in Cyprus flexible, horizontal decision making and discretion in the absence of a tight formal planning regulations characterise development processes. In the Greek paradigm, the promotion of a high volume of binding legal acts and processes that bypass the strict formal planning system facilitates the relatively fast delivery of the LUDs despite delays caused by reactions locally. Alternatively, in Cyprus, the existing loose regulating system which bypasses the official Development Plans becomes even more flexible in favor of large comprehensive developments with no formal legal mechanisms within the planning procedures to facilitate the interference of public opinion, leading to a very fast delivery of large projects.

In both, interrelated factors seem to influence the location and type of proposed LUDs: in Greece, to a limited number, large-scale tourist development outside urban areas toward rural and mainly undeveloped low-cost coastal areas; in Cyprus, to smaller-scale urban residential projects in urban areas. One last factor, which seems to affect outcomes, is the consolidated cultural perception of the spatial urban landscape and the level of influence towards its shape by local communities. Both the planning system and processes associated with LUDs reflect a much stronger cultural attitude in Greece toward "democratic" and direct involvement of citizens in civic affairs in comparison to Cyprus. In these terms, where the political trajectory of each region seems similar, fundamental difference in systems and real estate conditions also seem to lead to different outcomes in terms of the physical character and nature of the LUDs and their rate and ease of delivery.

The question of how far there is potential benefits in the future from the implementation of LUDs in localities remains open and controversial. In Greece, the investors' response to new LUD projects is limited so far, probably due to political and socio-economic realities. Furthermore, implications can only be assumed since very few large projects have been delivered recently. The future of LUDs in this context seems uncertain and perhaps relevant only in the long term. On the contrary, in Cyprus-where foreign investors responded rapidly to the opportunities for large projects-potential benefits seem limited to purely economic interests and mostly relevant to the real estate sector. The potential for area regeneration and the triggering of wider area renewal dynamics, positive cultural change or obvious benefit for the local community are apparently not possible. Lack of relevant research and available data also fails to verify the nature of the financial benefits of "spatial fixes" to the local economy.

The basic criticism of the current LUD policy in both countries, which is again a verification of the "spatial fix" concept, is that new processes are adopted because of pressures by international investors to avoid integrating projects with obvious impact on short term profitability. The integration of LUDs into the formal planning system not only could have secured a better "fit" of non-local investment but also had the potential to improve mechanism and inform a step change to local planning practice.

\section{Acknowledgments}

To all the anonymous public servants for the crucial inside information they have provided us with.

\section{Conflict of Interests}

The authors declare no conflict of interests.

\section{References}

Angelidis, M. (2000). Regional planning and sustainable development. Athens: Symmetria.

Büdenbender, M., \& Golubchikov, O. (2017). The geopolitics of real estate: Assembling soft power via property markets. International Journal of Housing Policy, 17(1), 75-96.

Clarno, A. (2019). The durability and dynamism of David Harvey. Contemporary Sociology, 48(4), 369-373.

Cooley, A., Heathershaw, J., \& Sharman, J. (2018) The rise of kleptocracy: Laundering cash, whitewashing reputations. Journal of Democracy, 29, 39-53.

Council of Ministers. (2016). Urban development incentives plan for the recovery of development activity in Cyprus (until 21/12/2016). Nicosia: Republic of Cyprus. 
Cyfield Group. (2019). 360 Nicosia. Cyfield Group. Retrieved from http://cyfieldgroup.com/project/360nicosia

Department of Town Planning and Housing. (2018a). Clarifying framework of general principles and conditions for the construction of tall buildings in urban areas of the four major urban bands. Nicosia: Department of Town Planning and Housing.

Department of Town Planning and Housing. (2018b). Building coefficients and large developments. Paper presented at Limassol Municipality Public Consultation, Limassol, Cyprus.

European Union. (1997). The EU compendium of spatial planning systems and policies. Luxembourg: European Commission.

Greek Industrialists' Association. (2018). Researches and studies. SEV. Retrieved from http://www.sev.org.gr/ vivliothiki-tekmiriosi/erevnes-meletes-2

Hadjimichalis, C. (2014). Crisis and land dispossession in Greece as part of the global 'land fever.' City, 18(4/5), 502-508.

Harris, M. (2019). A future for planning: Taking responsibility for twenty-first century challenges. New York, NY: Routledge.

Harvey, D. (2001). Globalization and the "spatial fix." Geographische Revue, 2, 23-30.

Hellenic Republic. (1975). The constitution of Greece (Government Gazette 111A/9.6.1975). Athens: Hellenic Republic.

Hellenic Republic. (2010). Acceleration and transparency in materialising strategic investments (Government Gazette, 204A/2.12.2010, Law 3894). Athens: Hellenic Republic.

Hellenic Republic. (2012). Development of Hellinicon exairport (Government Gazette, 70A/30.03.2012, Law 4062). Athens: Hellenic Republic.

Hellenic Republic. (2013). Adoption of the special spatial development plan (ESCHADA) for the public property of "Kassiopi Corfu" (Government Gazette, 406/AAP/15.11.2013). Athens: Hellenic Republic.

Hellenic Republic. (2014). Regional and urban planning reform: Sustainable development (Government Gazette, 142A/28.6.2014, Law 4269). Athens: Hellenic Republic.

Hellenic Republic. (2015). Adoption of the special spatial development plan (ESCHASE) for the strategic investment of "Killada Hills" (Government Gazette, 247/AAP/16.12.2015). Athens: Hellenic Republic.

Hellenic Republic. (2016a). Adoption of the planning study of the "Kassiopi Corfu" tourist village, tourist port facility, environmental terms and conditions for infrastructure projects (Government Gazette, 74/AAP/22.04.2016). Athens: Hellenic Republic.

Hellenic Republic. (2016b). Spatial planning, sustainable development and other provisions (Government Gazette, 241A/23.12.2016, Law 4447). Athens: Hellenic Republic.

Hellenic Republic. (2018). Adoption of the planning study of the "Killada Hills" tourist village, environmental terms and conditions for infrastructure projects (Government Gazette, 173/AAP/22.08.2018). Athens: Hellenic Republic.

Ioannidou, L. (2018, October 27). Limassol action group organises demo against high-rises. Cyprus Mail. Retrieved from https://cyprus-mail.com/old/2018/10/ 27/limassol-action-group-organises-demo-againsthigh-rises

loannou, B. (2016). Post-colonial urban development and planning in Cyprus: Shifting visions and realities of early suburbia. Urban Planning, 1(4), 79-88.

loannou, B. (2019). Ageing in suburban neighbourhoods: Planning, densities and place assessment. Urban Planning, 4(2), 18-30.

Ioannou, B., \& Nicolaou, L. (2018). Planning for Investors: Urban density and public space. Paper presented at "The urbanisation of (In)justice: Public Spaces in Uncertain Geographies" Conference, Nicosia, Cyprus.

Jessop, B. (2010). The 'return' of the national state in the current crisis of the world market. Capital \& Class, 34(1), 38-43.

Kalafsky, R. (2012). Expanding markets: Foreign direct investment as a lesson in economic geography. Journal of Geography, 111(4), 137-147.

Koudouni, A. (2014). Administration and responsibilities of spatial planning: Institutional issues, examples. $\mathrm{Na}$ tional Technical University of Athens-School of Architecture. Retrieved from http://www.arch.ntua.gr/ node-resources/1180\#resource-6731

Madanipour, A. (2006). Roles and challenges of urban design. Journal of Urban Design, 11(2), 173-193.

Mayer, M. (2017). Whose city? From Ray Pahl's critique of the Keynesian city to the contestations around neoliberal urbanism. The Sociological Review, 65(2), 168-183.

Melissas, D. (2010). Land uses, general urban plan and planning control zone. Athens: Sakkoulas.

Nethercote, M. (2018). Theorising vertical urbanisation. City, 22(5/6), 657-684.

Reimer, M., Getimis, P., \& Blotevogel, H. (Eds.). (2014). Spatial planning systems and practices in Europe: $A$ comparative perspective on continuity and changes. New York, NY: Routledge.

Republic of Cyprus. (1960). Constitution of the Republic of Cyprus. Nicosia: Republic of Cyprus.

Republic of Cyprus. (2014). Scheme for naturalization of investors in Cyprus by exception. Republic of Cyprus. Retrieved from http://www.moi.gov.cy/moi/ moi.nsf/All/1562764E412F7B6DC2257B80005235CF

Serraos, K. (2007). Urban planning studies according to the recent provisions in Greece. In A. Aravantinos (Ed.), Urban planning for a sustainable development of urban space (pp. 213-242). Athens: Symmetria.

Serraos, K. (2014). The recent provisions for the reform of the spatial planning system and the land use planning. In D. Melissas (Ed.), Land use: Spatial regulation for development (pp. 102-113). Athens: National 
Technical University of Athens.

Serraos, K., Greve, T., Asprogerakas, E., Balabanidis, D., \& Chani, A. (2015). Athens, a capital in crisis: Tracing the socio-spatial impacts. In J. Knieling \& F. Othengrafen (Eds.), Cities in crisis: Reflections on the socio-spatial impacts of the economic crisis and the strategies and approaches applied by Southern European cities (pp. 116-138). London: Routledge.
Sisson, A., Rogers, D., \& Gibson, C. (2019). Property speculation, global capital, urban planning and financialisation: Sydney boom, Sydney bust redux. Australian Geographer, 50(1), 1-9.

Spiliopoulou, G. (2018). Space as a place for investments: Special spatial tools for investments. Unpublished manuscript.

\section{About the Authors}

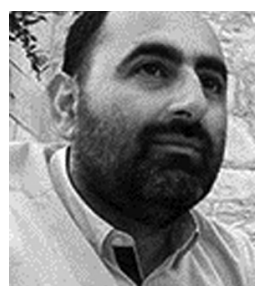

Byron loannou (PhD) is an Associate Professor at Frederick University. He has also taught Urban Design, Planning and Sustainable Built Environment in a number of universities of the Mediterranean region. $\mathrm{He}$ is an accredited expert on built environment by EU bodies, with a diverse portfolio on urban, coastal and countryside projects of different scales. His current research focuses on development plans and regulation processes, planning law and inclusive urban development, social and environmental aspects of urban space, density and sprawl.

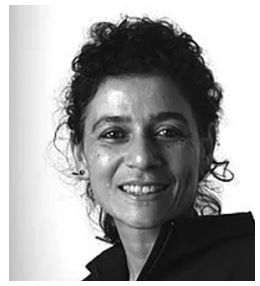

Lora Nicolaou (PhD) is an Assistant Professor of Urban Planning and Design at Frederick University. She was the Director of Urban Strategies at DEGW (London). In parallel she held the positions of the Head of Research for the Urban Renaissance Institute at the University of Greenwich. She taught at Coventry Polytechnic, Oxford Brookes University and the University of Cyprus. Her particular interest is the interpretation of user's needs \& preferences in a way that can intelligently inform building design and integrated development strategies.

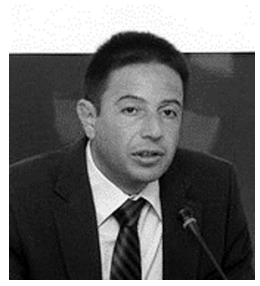

Konstantinos Serraos (PhD) is a Professor of Urban Planning \& Design at the National Technical University of Athens and Director of the Urban Planning Research Lab. He was the coordinator of the MSc in Environmental design of cities and buildings at the Hellenic Open University and the chairperson of the Environmental Awareness Park Antonis Tritsis and the Green Fund. His research focuses mainly on urban planning, environmental planning, land use, open space, urban regeneration, institutional planning, and the impact of socio-economic changes on space.

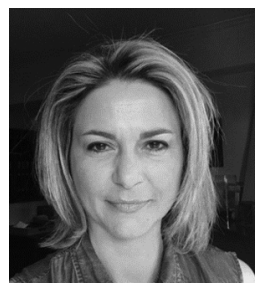

Georgia Spiliopoulou is an Architect working since 2002 at the planning sector of the Greek Ministry of Environment. She has also worked as a freelance architect in Athens and as a consultant in London. She holds a master's by the Bartlett School of Architecture (UCL) and is currently a PhD candidate at the National Technical University in Athens (NTUA). Her academic interests focus on legal certainty as a set of requirements for the organization and functioning of the urban planning system. 